\title{
MMP-9 genetic polymorphism may confer susceptibility to COPD
}

\author{
S. Jiang, Z.H. Yang, Y.Y. Chen, Z. He, Y. Zhou, Y. Gao, Q. Zhang and \\ M.Q. Tan \\ Second Department of Respiratory Medicine, \\ Shengjing Hospital of China Medical University, Shenyang, China \\ Corresponding author: M.Q. Tan \\ E-mail: tanmingqi_1021@163.com \\ Genet. Mol. Res. 15 (2): gmr.15026272 \\ Received October 26, 2015 \\ Accepted December 3, 2015 \\ Published April 25, 2016 \\ DOI http://dx.doi.org/10.4238/gmr. 15026272
}

\begin{abstract}
Correlations between genetic polymorphisms of three matrix metalloproteinase (MMP) genes and susceptibility to chronic obstructive pulmonary disease (COPD) were investigated. Relevant case-control studies were selected using rigorous inclusion and exclusion criteria. The comprehensive Meta-analysis 2.0 software was used to conduct the statistical analysis. An odds ratio with $95 \%$ confidence intervals was applied to assess the correlation between genetic polymorphisms of MMPs and susceptibility to COPD. Twelve high-quality studies were selected for inclusion in this meta-analysis. These studies included a combined total of 1533 COPD patients and 1530 healthy controls. The result of the meta-analysis showed that MMP-9 rs3918242 C > T was significantly correlated with increased susceptibility to COPD. However, $M M P-1$ rs $17997501 \mathrm{G}>2 \mathrm{G}$ and $M M P-3$ rs3025058 5A $>6 \mathrm{~A}$ were not associated with COPD risk (all $\mathrm{P}>0.05$ ). Based on our meta-analysis, $M M P-9$ rs3918242 C $>\mathrm{T}$ is correlated with susceptibility to COPD, but $M M P-1$ rs $17997501 \mathrm{G}>2 \mathrm{G}$ and $M M P-3$ rs3025058 5A > 6A are not. These results should be further confirmed using a larger sample size.
\end{abstract}

Key words: $M M P-1 ; M M P-3 ; M M P-9 ;$ COPD; rs3918242; rs1799750 


\section{INTRODUCTION}

Chronic obstructive pulmonary disease (COPD) is well known as a heterogeneous disease with pulmonary and extrapulmonary symptoms. COPD involves an intricate array of cellular, functional, and organ-related events that result in airflow limitation by virtue of a prolonged time constant of lung emptying (Garcia-Aymerich et al., 2011; Maclay et al., 2012). COPD is a chronic condition that affects approximately three million worldwide and current disease estimates show that COPD will be the third leading cause of death by 2020 (Singh et al., 2011; Vestbo et al., 2013). Curiously, the latest data show a steep increase in mortality rates of females compared to more modest increases in males within the same population (Alfageme et al., 2010). Several risk factors are directly linked to COPD pathogenesis and prominently include host and environmental factors (Brusselle et al., 2011). Environmental factors such as cigarette smoke, indoor and outdoor air pollution, and chemical exposure are high risk factors for COPD. Host factors mainly involve alpha-1 antitrypsin, excessive extracellular matrix (ECM) deposition, corticosteroids, inflammatory stimuli, and metabolic imbalance (Foreman et al., 2012; Gan et al., 2013). Matrix metalloproteinases (MMPs) and tissue inhibitors of metalloproteinases (TIMPs) have received significant attention in COPD research because MMPs and TIMPs play important opposing roles in regulating ECM synthesis and degradation (Wu et al., 2012; Abboud et al., 2013). Imbalances in ECM synthesis and degradation have severe consequences for tissue integrity and function. These imbalances can provoke sustained inflammatory responses; therefore, MMP and TIMP pathways are valuable therapeutic targets for COPD (Larsson-Callerfelt et al., 2013).

MMPs are a subfamily of zinc- and calcium-dependent enzymes with a potent capacity to degrade several ECM proteins. They are critical for normal biological functions such as embryonic development and tissue turnover (Hadler-Olsen et al., 2011; Leonetti et al., 2012). MMPs can regulate a wide variety of biological functions including the activity of inflammatory cytokines, tissue repair, epithelial barrier functions, chemokine activity, and morphogen gradients, and resolution of infection (Gómez-Piña et al., 2012). To date, 30 members of the MMP family have been identified. These MMPs have been grouped into major subclasses based on their substrate specificities, such as collagenases (MMP-1, -8, -13), stromelysins (MMP-3, -10, -11), gelatinases (MMP-2, -9), matrilysins (MMP-7, -26), and membrane-type MMPs (MMP-14, MMP-15, MMP-17). Three matrix metalloproteinases, MMP-1, MMP-3 and MMP-9, are among the most well-known proteins of the MMP family and are frequently associated with several disease states (Hemmann et al., 2007; Lia et al., 2009). MMP-1 and MMP-3 are located on chromosome 11q22.3. MMP-9 is synthesized as preproenzyme consisting of 707-amino acid residues and is the most complex member of the MMP family (Folseraas and Karlsen, 2011; Liu et al., 2012). Several studies have described the important roles MMPs play in various pathological and physiological processes, such as tissue repair, COPD, angiogenesis, and chronic inflammation (Dormán et al., 2010; Wu et al., 2012). However, the correlation between genetic polymorphisms of MMPs and susceptibility to COPD remains controversial (Schirmer et al., 2009; Cheng et al., 2009). In light of the conflicting data, we conducted a meta-analysis to investigate the correlation between genetic polymorphisms of MMPs and susceptibility to COPD. 


\section{MATERIAL AND METHODS}

\section{Data sources and key words}

The electronic databases, E.B. Stephens COmpany database (EBSCO), Ovid, Springerlink, Wiley, Web of Science, Wanfang databases, China National Knowledge Infrastructure (CNKI) databases, and Weipu databases (last updated search in November 2014) were systematically searched to retrieve articles that studied the correlation between MMPs and COPD. The search strategy used a combination of free words and key words. The elaborate search strategy was as follows: "matrix metalloproteinases" or "matrix metalloproteinase inhibitors" or "tissue inhibitor of metalloproteinases" or "MMPs" or "matrix metalloproteinases" or "matrix metalloproteinase inhibitors" or "MMP inhibitors" or "tissue inhibitor of metalloproteinases" or "TIMPs" and "pulmonary disease, chronic obstructive" or "COPD" or "chronic obstructive pulmonary disease" or "chronic obstructive lung disease" or "chronic obstructive airway disease" or "chronic airflow obstructions" or "COAD" and "polymorphism, genetic" or "polymorphism" or "SNP" or "mutation" or "variant" or "variation". Moreover, additional relevant studies were retrieved by a manual search of crossreferences.

\section{Inclusion and exclusion criteria}

All retrieved studies met the following selection criteria: 1) research type: case-control studies; 2) research topic: the correlation between polymorphisms of MMPs and susceptibility to COPD; 3 ) research objects: all cases should be verified as COPD patients by histopathology and the controls are healthy; 4) end outcomes: all enrolled studies provide site information of $M M P-9$ rs3918242 C > T, MMP-1 rs $17997501 \mathrm{G}>2 \mathrm{G}$, and $M M P-3$ rs3025058 5A > 6A. Articles with only a summary and abstract, duplicate publications, and studies with incomplete data were excluded.

\section{Data extraction and quality assessment}

Two investigators independently extracted all useful information under the preconcerted data collection list. The extracted information included the surname of first author, time of publication, country, ethnicity, language, diseases, the number of case and controls, age, detection methods, and single nucleotide polymorphisms (SNPs). A third investigator resolved any disagreements during the data extraction process through reexamination of all items and discussion. The quality of all included studies were independently assessed by two investigators based on critical appraisal skill program (CASP) criteria (http://www.casp-uk. net/) developed by Oxford Centre for Evidence Based Medicine. The study was evaluated by a third investigator or group if there was dissent among two or more investigators. The details of CASP are as follows: whether the study addressed a clearly focused issue (CASP01); whether an appropriate method was used to answer their question (CASP02); whether the cases were recruited in an acceptable way (CASP03); whether the controls were selected in an acceptable way (CASP04); whether the exposure was accurately measured to minimize bias (CASP05); what confounding factors the authors accounted for or how the authors accounted for potential 
confounding factors in the design and/or in their analysis (CASP06); the results of the study (CASP07); precision of the results (CASP08); believability of the results (CASP09); the application of the results to the local population (CASP10); the degree to which the results of the study fit with other available evidence (CASP11).

\section{Statistical analysis}

The comprehensive Meta-analysis 2.0 software (Biostatic Inc., Englewood, NJ, USA) was employed in our meta-analysis. The correlation between polymorphisms of MMPs and susceptibility to COPD was evaluated using the odds ratio (OR) and its $95 \%$ confidence intervals $(95 \% \mathrm{CI})$ under a fixed-effect model or a random-effect model. A Z-test was conducted to examine the significance of pooled standard mean differences. Forest plots displayed the comparison of the OR and its 95\%CI among all enrolled studies. The Cochran Q-statistic ( $\mathrm{P}<0.05$ was considered significant) and $I^{2}$ test $(0 \%$, no heterogeneity; $100 \%$, maximal heterogeneity) was conducted to evaluate the heterogeneity. A randomeffect model was applied when heterogeneity was significant $\left(\mathrm{P}<0.05\right.$ or $I^{2}$ test exhibited $>50 \%$ ) among the retrieved studies. A fixed-effect model was employed otherwise. The potential source of heterogeneity was analyzed by univariate and multivariate metaregression analysis and Monte Carlo simulations were utilized for further confirmation. Sensitivity analysis was conducted by individually deleting each included study to assess whether the overall results were influenced by single study. Funnel plots, classic fail-safe $\mathrm{N}$, and Egger linear regression tests were employed to ascertain potential publication bias to further confirm the result. All tests were two-sided and $\mathrm{P}$ values $<0.05$ were considered statistically significant.

\section{RESULTS}

\section{Baseline characteristics of included studies}

Following stringent selection criteria, the 79 studies, initially retrieved through electronic database searches and manual searches, were screened to eliminate seven duplicates, six letters and reviews, two non-human studies, and 11 irrelevant studies. After further rigorous screening, 41 studies were determined to be unrelated to our topic of interest. Finally, 12 case-control studies, published between 2004 and 2012, were selected for the present meta-analysis. These studies contained 1533 COPD patients and 1530 healthy controls (Zhou et al., 2004; Ito et al., 2005; Sun et al., 2005; Zhang et al., 2005; Han et al., 2006; Cheng et al., 2009; Santus et al., 2009; Schirmer et al., 2009; Cai et al., 2010; Hua et al., 2010; Lee et al., 2010; Sun et al., 2012). Sample sizes in the studies included in our meta-analysis ranged between 154 and 634. Two studies were performed on Caucasian populations and 10 studies examined Asian populations. The SNP analyses of all enrolled studies were performed by polymerase chain reaction with the restriction fragment length polymorphism (PCR-RFLP) and direct sequencing. The genotype distributions of the included studies were in conformity with Hardy Weinberg equilibrium (all $\mathrm{P}>0.05$ ), except for rs $17997501 \mathrm{G}>2 \mathrm{G}$ in Lee et al. (2010) $(\mathrm{P}<0.05)$. Baseline characteristics of all enrolled studies are listed in Table 1. 
Table 1. Baseline characteristics of all eligible studies.

\begin{tabular}{|c|c|c|c|c|c|c|c|c|c|c|c|}
\hline \multirow{2}{*}{ First author } & \multirow{2}{*}{ Year } & \multirow{2}{*}{ Country } & \multirow{2}{*}{ Ethnicity } & \multicolumn{2}{|c|}{ Number } & \multicolumn{2}{|c|}{ Gender (M/F) } & \multicolumn{2}{|c|}{ Age (years) } & \multirow{2}{*}{ Genotype methods } & \multirow{2}{*}{ Gene } \\
\hline & & & & Case & Control & Case & Control & Case & Control & & \\
\hline Sun CJ & 2012 & China & Asian & 80 & 74 & $50 / 30$ & $42 / 32$ & $67.40 \pm 7.21$ & $60.18 \pm 5.44$ & PCR-RFLP & MMP-3 \\
\hline Lee SY & 2010 & Korea & Asian & 80 & 90 & $72 / 8$ & $82 / 8$ & $66.3 \pm 7.1$ & $65.4 \pm 8.2$ & PCR-RFLP & MMP-1 \\
\hline Lee SY & 2010 & Korea & Asian & 80 & 90 & $72 / 8$ & $82 / 8$ & $66.3 \pm 7.1$ & $65.4 \pm 8.2$ & PCR-RFLP & MMP-9 \\
\hline Cai JL & 2010 & China & Asian & 180 & 96 & $142 / 38$ & $70 / 26$ & $61.59 \pm 8.38(41-82)$ & $59.78 \pm 9.52(37-83)$ & PCR-RFLP & MMP-1 \\
\hline Hua DM & 2010 & China & Asian & 301 & 333 & - & - & $65.7 \pm 8.0$ & $60.4 \pm 8.2$ & PCR-RFLP & MMP-9 \\
\hline Schirmer H & 2009 & Brazil & Caucasian & 111 & 101 & $72 / 39$ & $75 / 26$ & $64.8 \pm 10.1$ & $46.4 \pm 8.8$ & Direct sequence & MMP-3 \\
\hline Schirmer $\mathrm{H}$ & 2009 & Brazil & Caucasian & 111 & 101 & $72 / 39$ & $75 / 26$ & $64.8 \pm 10.1$ & $46.4 \pm 8.8$ & Direct sequence & MMP-9 \\
\hline Cheng SL & 2009 & China & Asian & 184 & 212 & $152 / 32$ & $182 / 30$ & $71.9 \pm 8.0$ & $69.2 \pm 8.0$ & PCR-RFLP & MMP-1 \\
\hline Cheng SL & 2009 & China & Asian & 184 & 212 & $152 / 32$ & $182 / 30$ & $71.9 \pm 8.0$ & $69.2 \pm 8.0$ & PCR-RFLP & MMP-3 \\
\hline Cheng SL & 2009 & China & Asian & 184 & 212 & $152 / 32$ & $182 / 30$ & $71.9 \pm 8.0$ & $69.2 \pm 8.0$ & PCR-RFLP & MMP-9 \\
\hline Santus P & 2009 & Italy & Caucasian & 147 & 133 & $121 / 26$ & $107 / 26$ & $69.3 \pm 8.3$ & $67.5 \pm 8.8$ & Direct sequence & MMP-3 \\
\hline Han WJ & 2006 & China & Asian & 60 & 52 & $44 / 16$ & $36 / 16$ & $59.5 \pm 8.8$ & $59.7 \pm 9.5$ & PCR-RFLP & MMP-9 \\
\hline Zhang RB & 2005 & China & Asian & 147 & 120 & $135 / 12$ & $110 / 10$ & $67.75 \pm 6.93$ & $65.02 \pm 7.69$ & PCR-RFLP & MMP-1 \\
\hline Zhang RB & 2005 & China & Asian & 147 & 120 & $135 / 12$ & $110 / 10$ & $67.75 \pm 6.93$ & $65.02 \pm 7.69$ & PCR-RFLP & MMP-9 \\
\hline Sun $\mathrm{PZ}$ & 2005 & China & Asian & 59 & 109 & $43 / 16$ & $73 / 36$ & $66.1(39-86)$ & $59.4(34-85)$ & PCR-RFLP & MMP-1 \\
\hline Ito I & 2005 & Japan & Asian & 84 & 85 & $81 / 3$ & $69 / 16$ & $68.9 \pm 7.9$ & $58.8 \pm 12.8$ & PCR-RFLP & MMP-9 \\
\hline Zhou M & 2004 & China & Asian & 100 & 98 & $98 / 2$ & $97 / 1$ & $62.15 \pm 9.87$ & $62.79 \pm 11.89$ & PCR-RFLP & MMP-9 \\
\hline
\end{tabular}

$\mathrm{PCR}-\mathrm{RFLP}=$ polymerase chain reaction with the restriction fragment length polymorphism; $\mathrm{M}=$ male; $\mathrm{F}=$ female.

\section{Correlation between $M M P-9$ rs3918242 C > T and susceptibility to COPD}

The correlation between MMP-9 rs3918242 C > T and susceptibility to COPD was reported in eight studies. A fixed-effect model was applied because of the absence of heterogeneity among the allele model and the dominant model (all $\mathrm{P}>0.05$ ). The result of the meta-analysis showed that MMP-9 rs3918242 C > T was associated with increased susceptibility to COPD (allele model: $\mathrm{OR}=1.363,95 \% \mathrm{CI}=1.155-1.608, \mathrm{P}<0.001$; dominant model: $\mathrm{OR}=1.472,95 \% \mathrm{CI}=1.214-1.785, \mathrm{P}<0.001)($ Table 2 and Figure 1$)$.

Table 2. Comparisons of genotype and allele frequencies between the case and the control groups on the correlations between MMP-9 rs3918242 C > T, MMP-1 rs1799750 1G > 2G, andMMP-3 rs3025058 5A > 6A and susceptibility to chronic obstructive pulmonary disease.

\begin{tabular}{|c|c|c|c|c|c|c|c|c|c|}
\hline & \multicolumn{3}{|c|}{ rs 1799750} & \multicolumn{3}{|c|}{ rs3025058 } & \multicolumn{3}{|c|}{ rs3918242 } \\
\hline & $\mathrm{OR}$ & $95 \% \mathrm{CI}$ & $\mathrm{P}$ & $\mathrm{OR}$ & $95 \% \mathrm{CI}$ & $\mathrm{P}$ & OR & $95 \% \mathrm{CI}$ & $\mathrm{P}$ \\
\hline $\mathrm{M}$ allele $v s \mathrm{~W}$ allele (Allele model) & 1.043 & $0.897-1.213$ & 0.587 & 0.953 & $0.774-1.173$ & 0.652 & 1.472 & $1.214-1.785$ & $<0.001$ \\
\hline $\mathrm{WM}+\mathrm{MM} v s \mathrm{WW}$ (Dominant model) & 1.059 & $0.845-1.327$ & 0.618 & 1.136 & $0.830-1.554$ & 0.426 & 1.363 & $1.155-1.608$ & $<0.001$ \\
\hline MM vs WW (Homozygous model) & 1.248 & $0.883-1.763$ & 0.21 & 0.849 & $0.550-1.308$ & 0.458 & 1.557 & $0.946-2.563$ & 0.081 \\
\hline MM $v s$ WM (Heterozygous model) & 0.998 & $0.761-1.308$ & 0.987 & 1.411 & $0.968-2.058$ & 0.074 & 0.997 & $0.597-1.664$ & 0.99 \\
\hline MM $v s$ WW + WM (Recessive model) & 1.045 & $0.810-1.350$ & 0.734 & 0.744 & $0.525-1.055$ & 0.097 & 1.328 & $0.823-2.145$ & 0.245 \\
\hline
\end{tabular}

$\mathrm{OR}=$ odds ratio; $95 \% \mathrm{CI}=95 \%$ confidence intervals.

\section{Correlation between $M M P-1$ rs1799750 1G > 2G and susceptibility to COPD}

The correlation between $M M P-1$ rs $17997501 \mathrm{G}>2 \mathrm{G}$ and susceptibility to COPD was reported in five studies. A heterogeneity test showed no heterogeneity under the allele model or the dominant model, therefore a fixed-effect model was employed (all $\mathrm{P}>0.05$ ). The result of the meta-analysis revealed no detectable correlation between MMP-1 rs1799750 1G $>2 \mathrm{G}$ and susceptibility to $\mathrm{COPD}$ (allele model: $\mathrm{OR}=1.043,95 \% \mathrm{CI}=0.897-1.213, \mathrm{P}=0.587$; dominant model: $\mathrm{OR}=1.059,95 \% \mathrm{CI}=0.845-1.327, \mathrm{P}=0.618)$ (Table 2 and Figure 1$)$. 
A

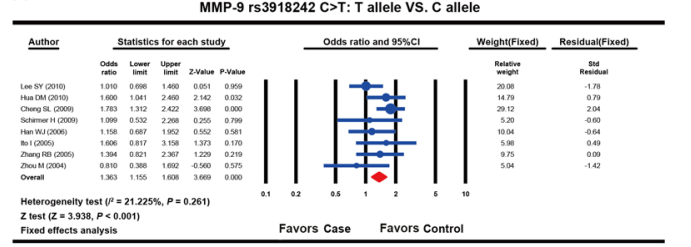

$\mathrm{C}$

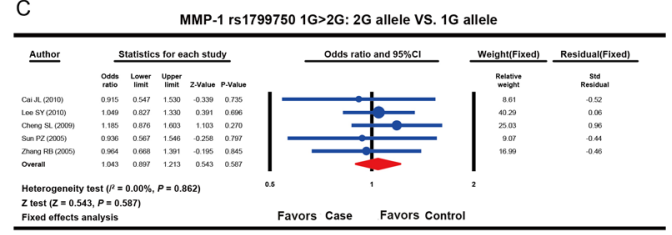

$Z$ tost $(Z=0.543, P=0.505, P$
Fixed effects analysis

E

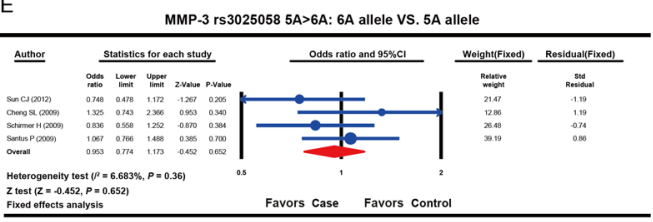

B

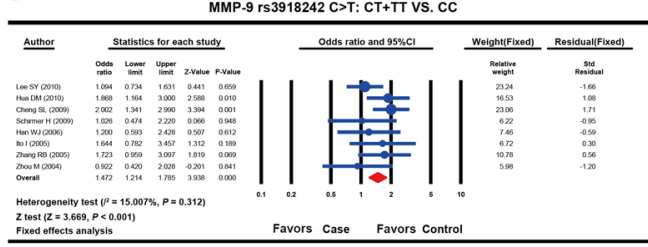

D

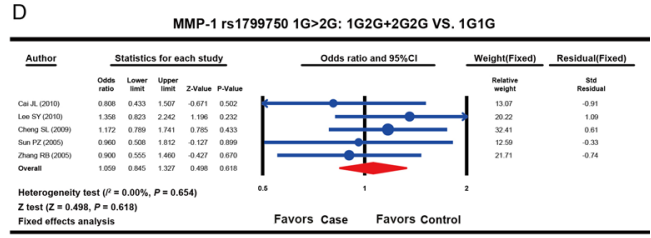

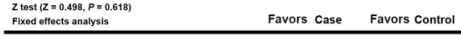

$\mathrm{F}$

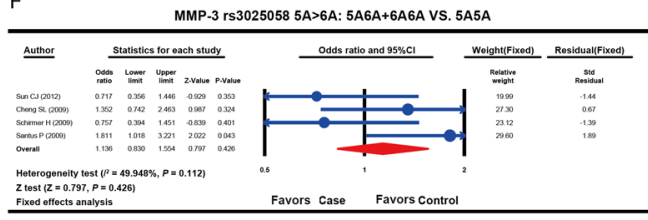

Figure 1. Forest plots of the correlation between genetic polymorphisms of $M M P-9$ rs $3918242 \mathrm{C}>\mathrm{T}, M M P-1$ rs $17997501 \mathrm{G}>2 \mathrm{G}$, and $M M P-3 \mathrm{rs} 30250585 \mathrm{~A}>6 \mathrm{~A}$ and susceptibility to chronic obstructive pulmonary disease.

\section{Correlation between $M M P-3$ rs3025058 5A > 6A and susceptibility of COPD}

The correlation between $M M P-3$ rs3025058 5A > 6A and susceptibility to COPD was reported in four studies. A fixed-effect model was employed because of the lack of heterogeneity among the allele model and the dominant model (all $\mathrm{P}>0.05$ ). The result of meta-analysis revealed no statistical correlation between $M M P-3$ rs $30250585 \mathrm{~A}>6 \mathrm{~A}$ and susceptibility to COPD (allele model: $\mathrm{OR}=0.953,95 \% \mathrm{CI}=0.774-1.173, \mathrm{P}=0.652$; dominant model: $\mathrm{OR}=1.136,95 \% \mathrm{CI}=0.830-1.554, \mathrm{P}=0.426)($ Table 2 and Figure 1$)$.

\section{Sensitivity analysis and publication bias}

The result of sensitivity analysis showed that all enrolled studies had no effect on pooled ORs of correlations between $M M P-9$ rs3918242 C > T, $M M P-1$ rs $17997501 \mathrm{G}>2 \mathrm{G}$, or $M M P-3$ rs3025058 5A $>6 \mathrm{~A}$ and susceptibility to COPD (Figure 2). Univariate meta-regression analysis showed that publication year, country, ethnicity, detection methods, SNP, and sample size were not the main source for heterogeneity nor were they key factors influencing the overall effect values $(\mathrm{P}>0.05)$. Multivariate meta-regression analysis further confirmed that the published year, country, ethnicity, sample size, SNP, and detection methods were not the sources of heterogeneity (Figure 3 and Table 3).

Funnel plots of $M M P-3$ rs3025058 5A $>6 \mathrm{~A}$ under a dominant model were asymmetric, suggesting the existence of publication bias. Classic fail-safe $\mathrm{N}$ and Egger linear regression tests further confirmed this bias (Figure 4). However, funnel plots of MMP-3 rs3025058 5A > 
Table 3. Meta-regression analyses of potential source of heterogeneity on the correlations between MMP-9 rs3918242 C > T, MMP-1 rs $17997501 \mathrm{G}>2 \mathrm{G}$, and $M M P-3$ rs3025058 5A > 6A and susceptibility to chronic obstructive pulmonary disease.

\begin{tabular}{l|c|c|c|c|c|c}
\hline \multirow{2}{*}{ Heterogeneity factors } & \multirow{2}{*}{ Coefficient } & \multirow{2}{*}{$\mathrm{SE}$} & \multirow{2}{*}{$t$} & \multicolumn{2}{|c}{ P5\% CI } \\
\cline { 5 - 7 } & & & & (Adjusted) & LL & UL \\
\hline Year & -0.04 & 0.035 & -1.15 & 0.785 & -0.117 & 0.037 \\
\hline Country & 0.028 & 0.083 & 0.34 & 0.998 & -0.156 & 0.212 \\
\hline Ethnicity & -0.302 & 0.313 & -0.97 & 0.878 & -0.999 & 0.395 \\
\hline Method & -0.042 & 0.174 & -0.24 & 1 & -0.43 & 0.346 \\
\hline SNP & -0.167 & 0.109 & -1.53 & 0.551 & -0.411 & 0.076 \\
\hline Sample & $<0.001$ & $<0.001$ & 1.17 & 0.776 & $<-0.001$ & 0.002 \\
\hline
\end{tabular}

$\mathrm{SE}=$ standard error; $\mathrm{LL}=$ lower limit; $\mathrm{UL}=$ upper limit; $\mathrm{SNP}=$ single nucleotide polymorphism.
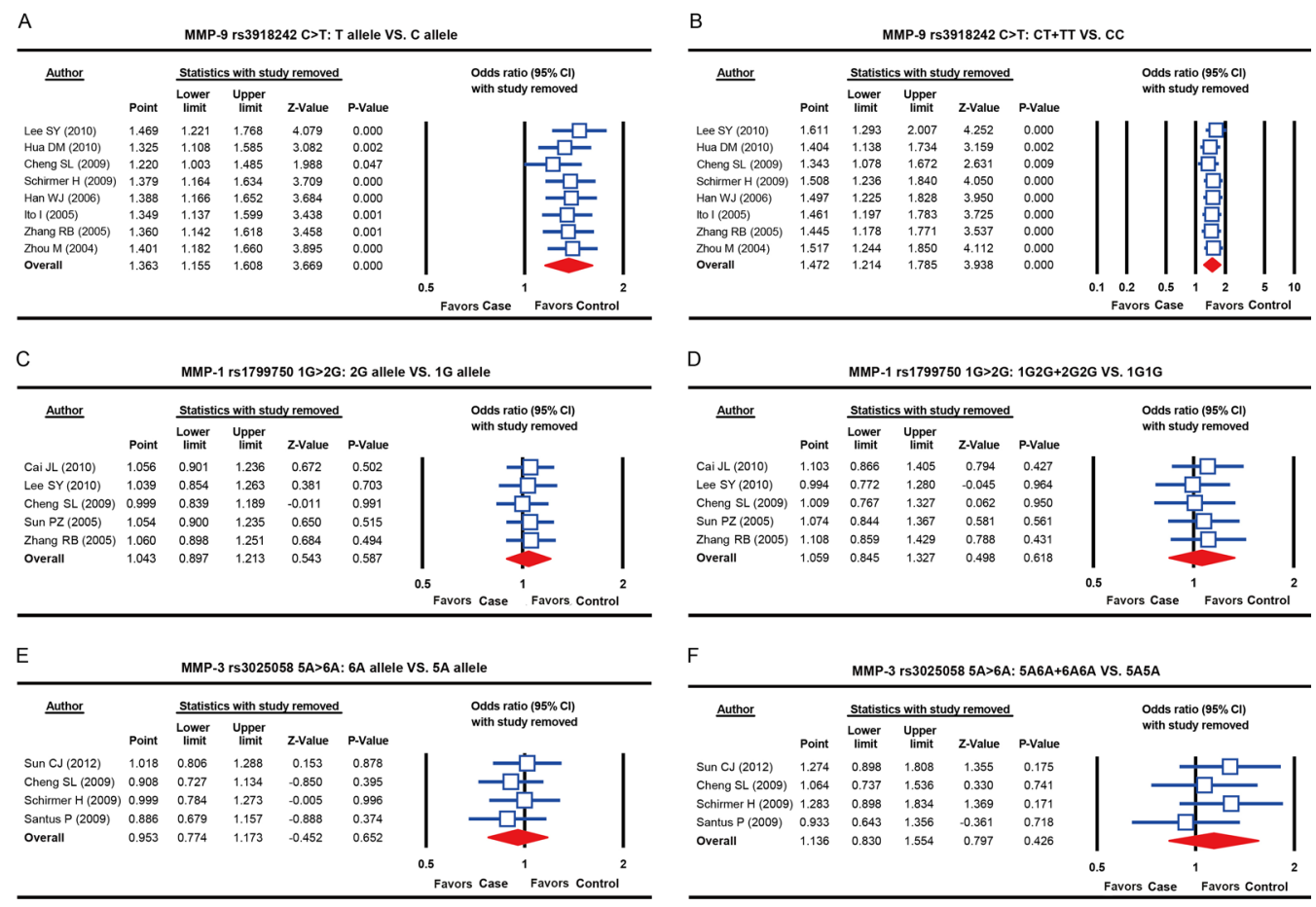

Figure 2. Sensitivity analysis for correlations between genetic polymorphisms of $M M P-9$ rs3918242 C $>$ T, $M M P$ $1 \mathrm{rs} 17997501 \mathrm{G}>2 \mathrm{G}$, and $M M P-3 \mathrm{rs} 30250585 \mathrm{~A}>6 \mathrm{~A}$ and susceptibility to chronic obstructive pulmonary disease.

$6 \mathrm{~A}$ under the allele model and $M M P-1 \mathrm{rs} 17997501 \mathrm{G}>2 \mathrm{G}$ and $M M P-3 \mathrm{rs} 30250585 \mathrm{~A}>6 \mathrm{~A}$ under allele and dominant models were symmetrical, indicating the absence of publication bias. Classic fail-safe $\mathrm{N}$ and Egger linear regression tests further confirmed our results (Figure 4). 

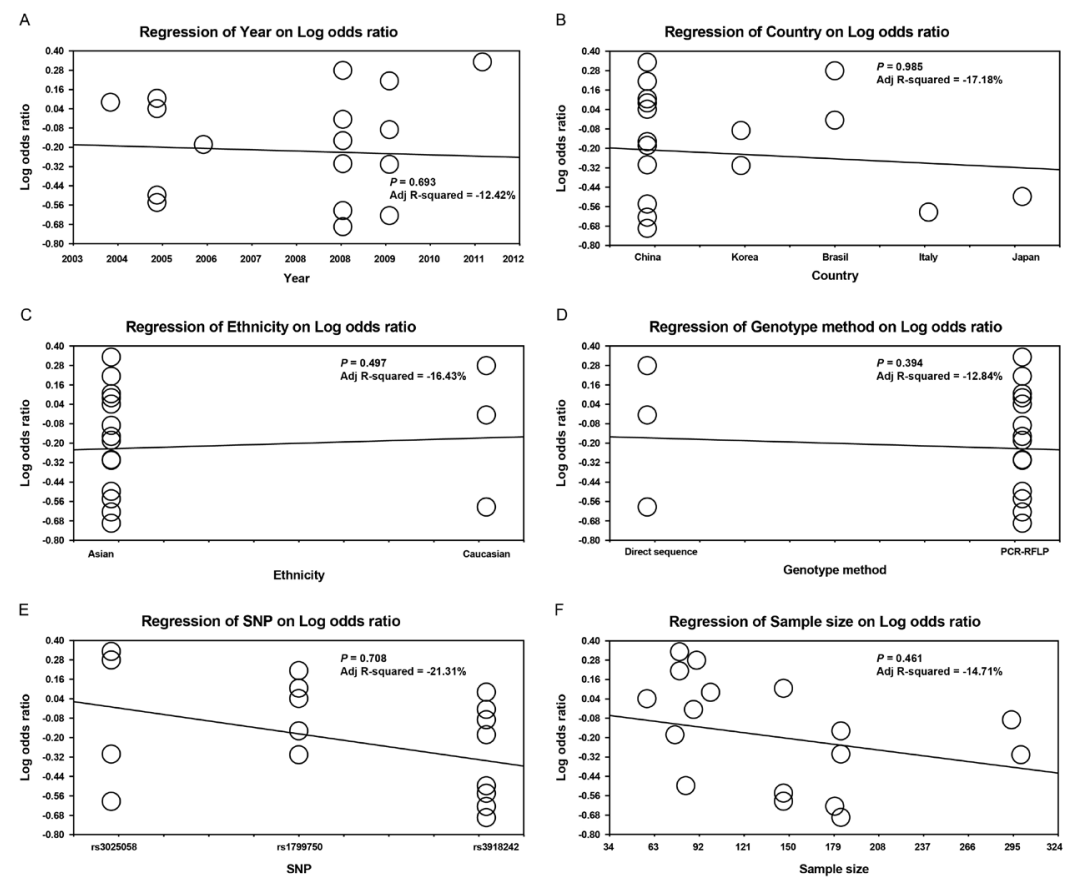

Figure 3. Meta-regression analysis of the correlations between genetic polymorphisms of $M M P-9$ rs 3918242 $\mathrm{C}>\mathrm{T}, M M P-1$ rs $17997501 \mathrm{G}>2 \mathrm{G}$, and $M M P-3 \mathrm{rs} 30250585 \mathrm{~A}>6 \mathrm{~A}$ and susceptibility to chronic obstructive pulmonary disease.
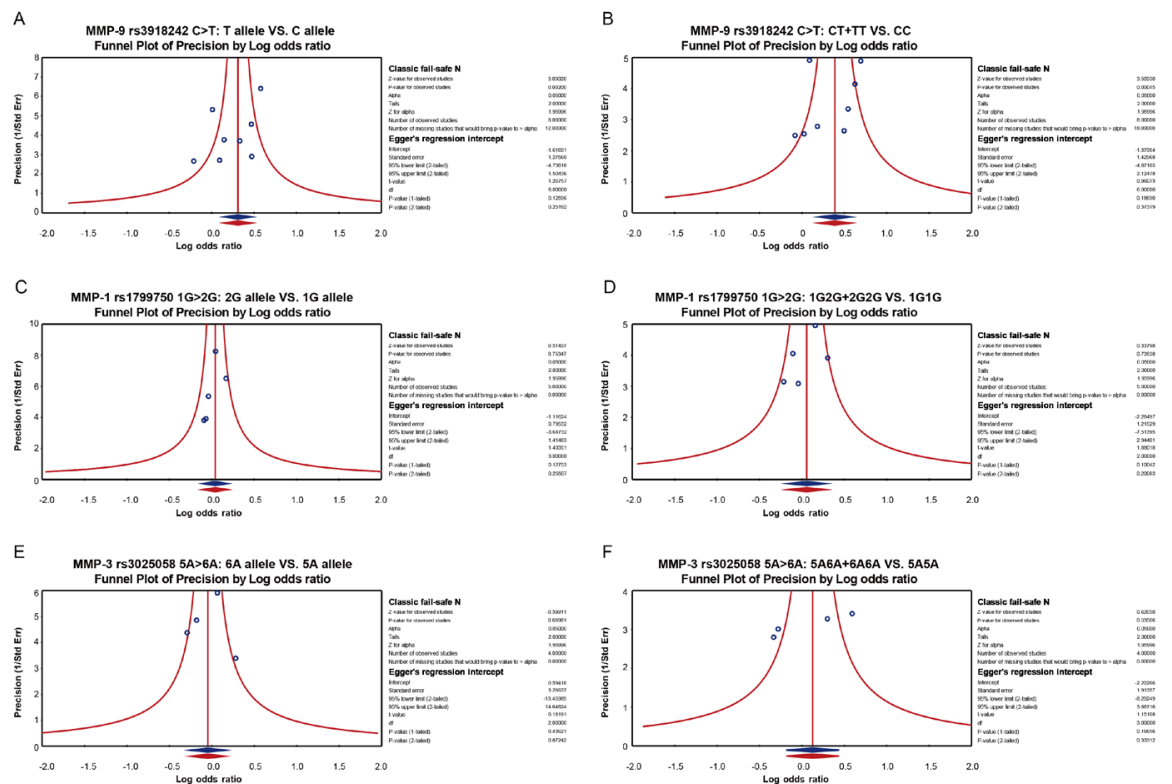

Figure 4. Publication biases of the correlations between genetic polymorphisms of $M M P-9$ rs $3918242 \mathrm{C}>\mathrm{T}, M M P-$ $1 \mathrm{rs} 17997501 \mathrm{G}>2 \mathrm{G}$, and $M M P-3 \mathrm{rs} 30250585 \mathrm{~A}>6 \mathrm{~A}$ and susceptibility to chronic obstructive pulmonary disease. 


\section{DISCUSSION}

A rigorous meta-analysis was conducted to correlate genetic polymorphisms of MMPs and susceptibility to COPD. The main result of our meta-analysis revealed that $M M P-9$ rs3918242 C > T is correlated with increased susceptibility to COPD, but no evident correlations were found between $M M P-1$ rs $17997501 \mathrm{G}>2 \mathrm{G}$ and $M M P-3$ rs $30250585 \mathrm{~A}>6 \mathrm{~A}$ polymorphisms and susceptibility to COPD. COPD is an incurable lung disease characterized by defective tissue repair, resulting in small airways fibrosis or emphysema (Singh et al., 2011; Brandsma et al., 2015). MMPs are a family of zinc-dependent proteins that mediate a variety of biological functions, including cell migration, cellular invasion, cytokine activation, and tissue damage repair (Clapper et al., 2011). MMP-9 is produced by many inflammatory cell types and epithelial cells, including alveolar macrophages, neutrophils, and macrophages. MMP-9 degrades elastin, bronchial epithelial cells, smooth muscle cells, and alveolar type II cells and plays a vital role in the development of emphysema (Cheng et al., 2009; Atkinson et al., 2011). MMP-9 is the main MMP released by macrophages and mediates tissue repair and remodeling via degradation of basement membrane type IV collagen and other ECM proteins (Brajer et al., 2008). MMP-9 may affect airflow limitation through degradation of alveolar ECM and components of the basement membrane, thus resulting in emphysema (Elkington et al., 2011). As the major rate-limiting enzyme in the MMP family, MMP-9 and its inhibitory factor TIMP1 play essential roles in remodeling airflows, and MMP-9 may contribute to inflammation and flow choking by increasing inflammatory corpuscles in the airway lumen or airway wall, damaging the epithelial/endothelial structure (Bourboulia and Stetler-Stevenson, 2010; Yao et al., 2013). Genetic polymorphisms of MMP-9 may affect the expression and activity of MMP9. $M M P-9$ rs3918242 C $>$ T may lead to the loss of binding of a nuclear repressor protein, thus resulting in the increased MMP-9 expression (Jacob-Ferreira et al., 2010). Our meta-analysis results, and other previous studies, show that high expression of MMP-9 rs3918242 C > T is correlated with increased susceptibility to COPD, and thus polymorphisms that hyper-activate MMP-9 pathways pose a high risk and exacerbate COPD pathogenesis.

There are some limitations that deserve further consideration. First, the sample size in our meta-analysis is relatively small, which influence the analyses. In addition, all high quality studies were either in English or in Chinese, potentially leading to language bias by ignoring unpublished studies and studies in other languages. Furthermore, the different genotyping methods applied in our meta-analysis may have introduced bias. Finally, incomplete data may have affected the final results.

In conclusion, the results of our meta-analysis provide strong evidence that $M M P$ 9 rs3918242 C $>\mathrm{T}$ is correlated with increased susceptibility to COPD, but the association of $M M P-1$ rs1799750 $1 \mathrm{G}>2 \mathrm{G}$ and $M M P-3 \mathrm{rs} 3025058$ 5A $>6 \mathrm{~A}$ with COPD risk was not statistically significant. These results may require confirmation from a future analysis with a larger sample size.

\section{Conflicts of interest}

The authors declare no conflict of interest.

\section{ACKNOWLEDGMENTS}

The authors wish to thank all study participants and all helpful comments from our reviewers. 


\section{REFERENCES}

Abboud R, Wallace A, English J, Harvey OC, et al. (2013). Secretion of mmps, cathepsins, and their inhibitors by alveolar macrophages and their association with emphysema. Am. J. Respir. Crit. Care Med. 187: A3486.

Alfageme I, Reyes N, Merino M, Reina A, et al. (2010). The effect of airflow limitation on the cause of death in patients with COPD. Chron. Respir. Dis. 7: 135-145. http://dx.doi.org/10.1177/1479972310368692

Atkinson JJ, Lutey BA, Suzuki Y, Toennies HM, et al. (2011). The role of matrix metalloproteinase-9 in cigarette smokeinduced emphysema. Am. J. Respir. Crit. Care Med. 183: 876-884. http://dx.doi.org/10.1164/rccm.201005-0718OC

Bourboulia D and Stetler-Stevenson WG (2010). Matrix metalloproteinases (MMPs) and tissue inhibitors of metalloproteinases (TIMPs): Positive and negative regulators in tumor cell adhesion. Semin. Cancer Biol. 20: 161168. http://dx.doi.org/10.1016/j.semcancer.2010.05.002

Brajer B, Batura-Gabryel H, Nowicka A, Kuznar-Kaminska B, et al. (2008). Concentration of matrix metalloproteinase-9 in serum of patients with chronic obstructive pulmonary disease and a degree of airway obstruction and disease progression. J. Physiol. Pharmacol. 59 (Suppl 6): 145-152.

Brandsma CA, van den Berge M, Postma DS, Jonker MR, et al. (2015). A large lung gene expression study identifying fibulin-5 as a novel player in tissue repair in COPD. Thorax 70:21-32. http://dx.doi.org/10.1136/thoraxjnl-2014-205091

Brusselle GG, Joos GF and Bracke KR (2011). New insights into the immunology of chronic obstructive pulmonary disease. Lancet 378: 1015-1026. http://dx.doi.org/10.1016/S0140-6736(11)60988-4

Cai JL, Wang HL and Wang AP (2010). Relationship between mmp-1 genetic polymorphism with the susceptibility of COPD of 80 Han natioanality in Jiangxi province. Shandong Med. J. 50: 76-77.

Cheng SL, Yu CJ and Yang PC (2009). Genetic polymorphisms of cytochrome p450 and matrix metalloproteinase in chronic obstructive pulmonary disease. Biochem. Genet. 47: 591-601. http://dx.doi.org/10.1007/s10528-009-9252-4

Clapper ML, Hensley HH, Chang WC, Devarajan K, et al. (2011). Detection of colorectal adenomas using a bioactivatable probe specific for matrix metalloproteinase activity.Neoplasia 13: 685-691. http://dx.doi.org/10.1593/neo.11400

Dormán G, Cseh S, Hajdú I, Barna L, et al. (2010). Matrix metalloproteinase inhibitors: a critical appraisal of design principles and proposed therapeutic utility. Drugs 70: 949-964. http://dx.doi.org/10.2165/11318390-000000000-00000

Elkington P, Shiomi T, Breen R, Nuttall RK, et al. (2011). MMP-1 drives immunopathology in human tuberculosis and transgenic mice. J. Clin. Invest. 121: 1827-1833. http://dx.doi.org/10.1172/JCI45666

Folseraas T and Karlsen TH (2011). To MMP or not to MMP: a role for matrix metalloproteinase 3 in primary sclerosing cholangitis? Liver Int. 31: 751-754. http://dx.doi.org/10.1111/j.1478-3231.2011.02471.x

Foreman MG, Campos M and Celedón JC (2012). Genes and chronic obstructive pulmonary disease. Med. Clin. North Am. 96: 699-711. http://dx.doi.org/10.1016/j.mcna.2012.02.006

Gan WQ, FitzGerald JM, Carlsten C, Sadatsafavi M, et al. (2013). Associations of ambient air pollution with chronic obstructive pulmonary disease hospitalization and mortality. Am. J. Respir. Crit. Care Med. 187: 721-727. http:// dx.doi.org/10.1164/rccm.201211-2004OC

Garcia-Aymerich J, Gómez FP, Benet M, Farrero E, et al. (2011). Identification and prospective validation of clinically relevant chronic obstructive pulmonary disease (COPD) subtypes. Thorax 66: 430-437. http://dx.doi.org/10.1136/ thx.2010.154484

Gómez-Piña V, Martínez E, Fernández-Ruíz I, Del Fresno C, et al. (2012). Role of MMPs in orchestrating inflammatory response in human monocytes via a TREM-1-PI3K-NF-אB pathway. J. Leukoc. Biol. 91: 933-945. http://dx.doi. org/10.1189/jlb.0711340

Hadler-Olsen E, Fadnes B, Sylte I, Uhlin-Hansen L, et al. (2011). Regulation of matrix metalloproteinase activity in health and disease. FEBS J. 278: 28-45. http://dx.doi.org/10.1111/j.1742-4658.2010.07920.x

Han WJ, Kuan gJL and Rao WH (2006). Relevance between matrix metalloproteinase 9 and the susceptibility of COPD. Chin. J. Tuberc. Respir. Dis. 29: 277-278.

Hemmann S, Graf J, Roderfeld M and Roeb E (2007). Expression of MMPs and TIMPs in liver fibrosis - a systematic review with special emphasis on anti-fibrotic strategies. J. Hepatol. 46: 955-975. http://dx.doi.org/10.1016/j. jhep.2007.02.003

Hua DM, Ding LY, Wang Z, Lv FZ, et al. (2010). Association of MMP-9 polymorphisms with susceptibility to chronic obstructive pulmonary disease in Ethnic Tibetan population. Int. J. Respir. 30: 1157-1160.

Ito I, Nagai S, Handa T, Muro S, et al. (2005). Matrix metalloproteinase-9 promoter polymorphism associated with upper lung dominant emphysema. Am. J. Respir. Crit. Care Med. 172: 1378-1382. http://dx.doi.org/10.1164/rccm.200506-953OC

Jacob-Ferreira AL, Passos CJ, Gerlach RF, Barbosa F Jr, et al. (2010). A functional matrix metalloproteinase (MMP)-9 polymorphism modifies plasma MMP-9 levels in subjects environmentally exposed to mercury. Sci. Total Environ. 408: 4085-4092. http://dx.doi.org/10.1016/j.scitotenv.2010.05.036 
Larsson-Callerfelt AK, Hallgren O, Andersson-Sjöland A, ThimanL, et al. (2013). Defective alterations in the collagen network to prostacyclin in COPD lung fibroblasts. Respir. Res. 14: 21. http://dx.doi.org/10.1186/1465-9921-14-21

Lee SY, Kim MJ, Kang HG, Yoo SS, et al. (2010). Polymorphisms in matrix metalloproteinase-1, -9 and -12 genes and the risk of chronic obstructive pulmonary disease in a Korean population. Respiration 80: 133-138. http://dx.doi. org $/ 10.1159 / 000284926$

Leonetti F, Muncipinto G, Stefanachi A, Nicolotti O, et al. (2012). Toward a fragment-based approach to MMPs inhibitors: an expedite and efficient synthesis of $N$-hydroxylactams. Tetrahedron Lett. 53: 4114-4116. http://dx.doi. org/10.1016/j.tetlet.2012.05.124

Lia NG, Shib ZH, Tang YP and Duan JA (2009). Selective matrix metalloproteinase inhibitors for cancer. Curr. Med. Chem. 16: 3805-3827. http://dx.doi.org/10.2174/092986709789178037

Liu D, Guo H, Li Y, Xu X, et al. (2012). Association between polymorphisms in the promoter regions of matrix metalloproteinases (MMPs) and risk of cancer metastasis: a meta-analysis. PLoS One 7: e31251.http://dx.doi. org/10.1371/journal.pone.0031251

Maclay JD, McAllister DA, Rabinovich R, Haq I, et al. (2012). Systemic elastin degradation in chronic obstructive pulmonary disease. Thorax 67: 606-612. http://dx.doi.org/10.1136/thoraxjnl-2011-200949

Santus P, Casanova F, Biondi ML, Blasi F, et al. (2009). Stromelysin-1 polymorphism as a new potential risk factor in progression of chronic obstructive pulmonary disease. Monaldi Arch. Chest Dis. 71: 15-20.

Schirmer H, Basso da Silva L, Teixeira PJ, Moreira JS, et al. (2009). Matrix metalloproteinase gene polymorphisms: lack of association with chronic obstructive pulmonary disease in a Brazilian population. Genet. Mol. Res. 8: 1028-1034. http://dx.doi.org/10.4238/vol8-3gmr596

Singh S, Loke YK, Enright PL and Furberg CD (2011). Mortality associated with tiotropium mist inhaler in patients with chronic obstructive pulmonary disease: systematic review and meta-analysis of randomised controlled trials. $B M J$ 342: d3215. http://dx.doi.org/10.1136/bmj.d3215

Sun CJ, Wang WM, Yang JP, Si QGW, et al. (2012). The association of matrix metalloproteinase 3, 12 polymorphism with susceptibility of chronic obstructive pulmonary disease. Chin. J. Clin. Electron. Ed. 6: 5826-5830.

Sun PZ, Chen J, Chen RY, Ji JJ, et al. (2005). The relevance of matrix metalloproteinase 9 gene polymorphisms with susceptibility of chronic obstructive pulmonary disease in Han nationality of northern China. Chin. J. Respir. Crit. Care Med. 5: 342-344.

Vestbo J, Hurd SS, Agustí AG, Jones PW, et al. (2013). Global strategy for the diagnosis, management, and prevention of chronic obstructive pulmonary disease: GOLD executive summary. Am. J. Respir. Crit. Care Med. 187: 347-365. http://dx.doi.org/10.1164/rccm.201204-0596PP

$\mathrm{Wu}$ Y, Li J, Wu J, Morgan P, et al. (2012). Discovery of potent and selective matrix metalloprotease 12 inhibitors for the potential treatment of chronic obstructive pulmonary disease (COPD). Bioorg. Med. Chem. Lett. 22: 138-143. http:// dx.doi.org/10.1016/j.bmcl.2011.11.046

Yao H, Hwang JW, Sundar IK, Friedman AE, et al. (2013). SIRT1 redresses the imbalance of tissue inhibitor of matrix metalloproteinase-1 and matrix metalloproteinase-9 in the development of mouse emphysema and human COPD. Am. J. Physiol. Lung Cell. Mol. Physiol. 305: L615-L624. http://dx.doi.org/10.1152/ajplung.00249.2012

Zhang RB, He QY, Yang RH, Lu BB, et al. (2005). Study on matrix metalloproteinase 1, 9, 12 polymorphisms and susceptibility to chronic obstructive pulmonary disease among Han nationality in northern China. Zhonghua Liu Xing Bing Xue Za Zhi 26: 907-910.

Zhou M, Huang SG, Wan Hy, Li B, et al. (2004). Correlation between genetic polymorphism in MMP-9 and susceptibility to COPD in southern Chinese population of Han nationality of China. Acad. J. Shanghai Second Med. Univ. 24: 81-84. 